$\mathrm{AB} 0787$

THE EULAR SYSTEMIC SCLEROSIS IMPACT OF DISEASE (SCLEROID) SCORE - A NEW PATIENTREPORTED OUTCOME MEASURE FOR PATIENTS WITH SYSTEMIC SCLEROSIS

R. Dobrota ${ }^{1}$, M.O. Becker ${ }^{1}$, K. Fligelstone ${ }^{2}$, J. Fransen ${ }^{3}$, A. Tyrrell Kennedy ${ }^{4}$, Y. Allanore ${ }^{5}$, P. Carreira ${ }^{6}$, L. Czirjak ${ }^{7}$, C. Denton ${ }^{8}$, R. Hesselstrand ${ }^{9}$, G. Sandqvist ${ }^{9}$, O. Kowal-Bielecka ${ }^{10}$, C. Bruni ${ }^{11}$, M. Matucci-Cerinic ${ }^{11}$, C. Mihai ${ }^{1}$, A. Gheorghiu ${ }^{12}$, U. Müller-Ladner ${ }^{13}$, M. Vonk ${ }^{3}$, I. Olsen ${ }^{14}$, T. Heiberg ${ }^{15}$, O. Distler ${ }^{1} .{ }^{1}$ Rheumatology, UNIVERSITY HOSPITAL ZUERICH, Zuerich, Switzerland; ${ }^{2}$ Royal Free London NHS Foundation Trust, London, UK: ${ }^{3}$ Rheumatology, Radboud University Medical Center, Nijmegen, Netherlands; ${ }^{4}$ Federation of European Scleroderma Associations, Dublin, Ireland; ${ }^{5}$ Rheumatology, University Paris Descartes and Cochin Hospital, Paris, France; ${ }^{6}$ Rheumatology, Hospital Universitario 12 de Octubre and Universidad Complutense de Madrid, Madrid, Spain; ${ }^{7}$ Immunology and Rheumatology, Faculty of Medicine, University of Pécs, Pécs, Hungary; ${ }^{8}$ Rheumatology, Royal Free and University College London Medical School, Royal Free Campus, London, UK; ${ }^{9}$ Rheumatology, Lund University, Lund, Sweden; ${ }^{10}$ Department of Rheumatology and Internal Medicine, Medical University of Bialystok, Bialystok, Poland; ${ }^{11}$ Rheumatology, University of Florence, Florence, Italy; ${ }^{12}$ Internal Medicine and Rheumatology, Cantacuzino Hospital, Carol Davila University of Medicine and Pharmacy, Bucharest, Romania; ${ }^{13}$ Rheumatology and Clinical Immunology, Justus-Liebig University Giessen, Kerckhoff-Klinik Bad Nauheim, Bad Nauheim, Germany, ${ }^{14}$ Research Support Services CTU, Oslo University Hospital; ${ }^{15} \mathrm{Health}$ and Social Sciences, Oestfold University College, Oslo, Norway

Background: Patient reported outcome measures (PROs) are increasingly important for clinical practice and research. Given the unmet need for a comprehensive PRO for systemic sclerosis (SSc), the SclerolD questionnaire was developed by a joint team of patients with SSc and medical experts in the field. This approach was designed as a brief, specific, patient-derived, disease impact score for research and clinical use in SSc. A preliminary analysis was previously reported. Here, we present the first computation of the ScleroID score and an extended pre-final analysis from the ongoing SclerolD validation study.

Methods: This EULAR-endorsed project involves 11 European expert SSc centres. Patients fulfilling the ACR/EULAR 2013 criteria were prospectively included since $05 / 16$ in the ongoing observational cohort study. Patients completed the ScleroID questionnaire (figure 1), as well as the selected comparators mSHAQ, EQ5D, and SF36. Additionally, they weighted the 10 dimensions of the SclerolD by distributing 100 points according to the perceived impact on their health. The final score calculation was based on the ranking of the weights. The study included a reliability arm (follow-up questionnaire 7-10 days from baseline), as well as a longitudinal arm, looking at sensitivity to change at follow-up visits after 6 and 12 months from baseline.

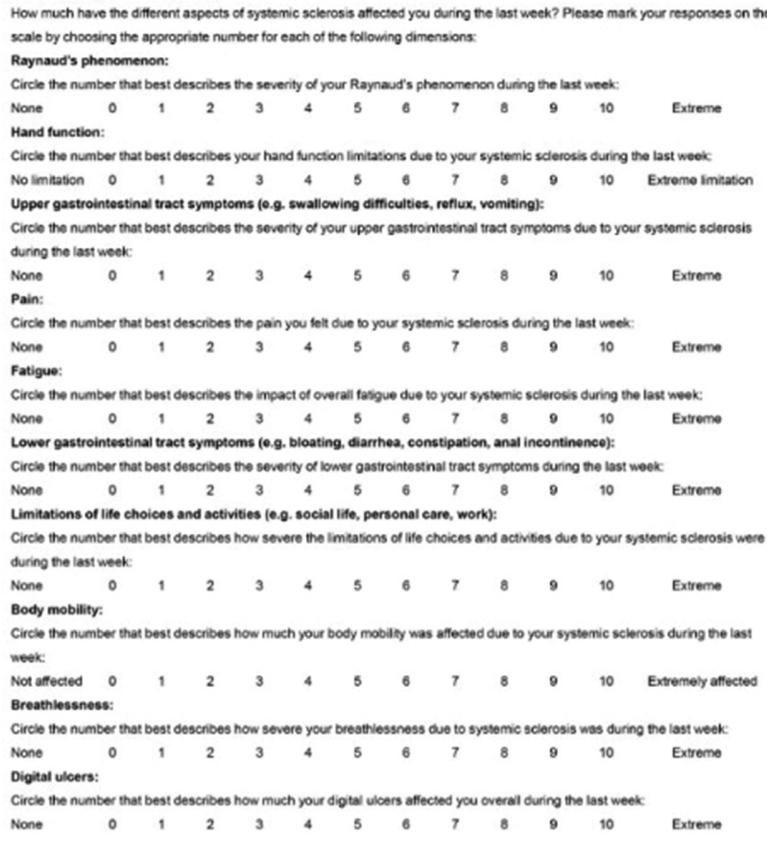

Abstract AB0787 - Figure 1. The EULAR Scleroderma Impact of Disease Score (SclerolD) visit. $84 \%$ of patients were female, $62 \%$ had limited cutaneous SSc, mean age was 56 years, and median disease duration 10 years. $19 \%$ of patients were not able to work. The highest weights by the patients were assigned to Raynaud's phenomenon, fatigue, hand function and pain, in accordance with our previous results. The total ScleroID score showed good Spearman correlation coefficients with the comparators (mSHAQ, 0.59; EQ5D -0.62; Patient's global assessment VAS 0.75 ; SF36 physical score -0.62 ; each $p<0.001$ ). The internal consistency was good with a high Crohnbach's alpha by 0.86 .

Conclusions: The EULAR SclerolD score is a promising, novel PRO too designed for use in clinical practice and clinical trials to display the disease impact of SSc, showing good performance in this pre-final analysis. Importantly, Raynaud's phenomenon, impaired hand function, pain and fatigue were the main patient reported drivers of disease impact. To date the recruitment has reached more than $80 \%$ of the targeted number, the study is ongoing.

Disclosure of Interest: R. Dobrota: None declared, M. Becker: None declared, K. Fligelstone: None declared, J. Fransen: None declared, A. Tyrrell Kennedy: None declared, Y. Allanore Grant/research support from: Bristol-Myers Squibb, Roche/Genentech, Inventiva, Pfizer, Sanofi, and Servier, Consultant for: Actelion, Bayer, Roche/Genentech, Inventiva, Medac, Pfizer, Sanofi, Servier, and UCB, P Carreira: None declared, L. Czirjak: None declared, C. Denton Consultant for: Roche/Genentech, Actelion, GlaxoSmithKline, Sanofi-Aventis, Inventiva, Boeh ringer-Ingelheim, CSL Behring, EMD Serono, Inventiva, and UCB Pharma, R Hesselstrand: None declared, G. Sandqvist: None declared, O. Kowal-Bielecka: None declared, C. Bruni: None declared, M. Matucci-Cerinic: None declared, C Mihai: None declared, A. Gheorghiu: None declared, U. Müller-Ladner: None declared, M. Vonk: None declared, I. Olsen: None declared, T. Heiberg: None declared, O. Distler Grant/research support from: Actelion, Bayer, Boehringer Ingelheim, Mitsubishi Tanabe Pharma and Roche, Consultant for: Actelion, Bayer Biogenldec, Boehringer Ingelheim, ChemomAb, espeRare foundation, Genentech/Roche, GSK, Inventiva, Italfarmaco, Lilly, medac, Medlmmune, Mitsubishi Tanabe Pharma, Pharmacyclics, Novartis, Pfizer, Sanofi, Sinoxa and UCB DOI: 10.1136/annrheumdis-2018-eular.6368

\section{AB0788 OSTEOARTICULAR INVOLVEMENTS IN PATIENTS WITH SYSTEMIC SCLEROSIS}

M. Tougorti, T. Ben Salem, I. Ben Ghorbel, M. Lamloum, M.H. Houman. Internal medecine, RABTA HOSPITAL, Tunis, Tunisia

Background: Osteoarticular involvements are common in systemic sclerosis (SS) and are considered as an important cause of disability

Objectives: The aim of this study was to assess clinical, radiological and immunological characteristics of patients with systemic sclerosis and who present with osteoarticular involvements at any time of the disease course. Patients with arthralgia and/or arthritis and/or imaging abnormalities were included.

Methods: A retrospective descriptive and comparative study was performed in an internal medicine department. One hundred thirty one patients who fulfilled 2013 ACR/EULAR criteria for SS were studied.

Results: We identified 101 patients with osteoarticular involvements (77.1\%); 92 women and 9 men. Mean age at SS diagnosis was $47.6 \pm 12.4$ years. Disease was revealed by joint manifestations in $10.7 \%$ of cases. Arthralgia and arthritis were observed in $61.8 \%$ and $21.4 \%$ of cases respectively. Flexion deformities with disability were noted in 26 cases. X-Ray investigations revealed distal phalanges resorption $(n=24)$, dystrophic calcifications $(n=10)$ and joint space narrowing $(n=9)$. Tendinitis was observed in one patient. Patients with osteoarticular manifestations developed more frequently digital ulcers (100\% vs $78.3 \% ; p<0.001)$. Osteoarticular involvements was associated to diffuse cutaneous sclerosis ( $37.7 \%$ vs $12.5 \% ; p=0.002$ ) and to telangiectasis $(91.3 \%$ vs $70 \% ; p=0.027$ ), gastrointestinal manifestations ( $90.1 \%$ vs $54.5 \%$; $p=0.001)$ and interstitial lung disease $(92.7 \%$ vs $67.9 \%$; $p=0.001)$. SS was associated to sjögren syndrome $(n=20)$, to systemic lupus erythematosus $(n=15)$ and to rheumatoid arthritis $(n=2)$. Patients received non-steroidal anti-inflammatory drug $(n=26)$, corticosteroids $(\mathrm{n}=8)$ and methotrexate $(\mathrm{n}=8)$.

Conclusions: Osteoarticular involvement in systemic sclerosis has heterogeneous aspects. Its frequency ranges from $40 \%$ to more than $85 \%$ of cases in some studies. Early screening and treatment associated with physiotherapy session are essential to avoid complication and loss of function.

Disclosure of Interest: None declared

DOI: 10.1136/annrheumdis-2018-eular.4970 